\title{
LETRAMENTO DIGITAL E A FORMAÇÃO DO PROFESSOR DE LÍNGUA NA CONTEMPORANEIDADE
}

\section{Patricia Fabiana BEDRAN *}

- RESUMO: Na tentativa de contemplar e repensar a formação do professor sob um viés mais contemporâneo, objetivamos promover uma discussão, a partir da reflexão e articulação de conceitos e perspectivas sobre Letramento Digital (STREET, 1995; BUZATO, 2006; ROJO, 2013) e a Formação Sociocultural do Professor (VIGOTSKI, 1998; 2010; JOHNSON, 2009; FRIEDRICH, 2012), no que se refere ao uso da tecnologia da informação e da comunicação (LÉVY, 1998; 1999; 2007) como responsável por (novas) práticas de letramento no âmbito educacional. De forma a instigar uma reflexão sobre a experiência prática à luz da literatura da área, tecemos consideraçóes mais pontuais sobre uma pesquisa qualitativa de cunho etnográfico, realizada em um contexto de formação inicial do profissional de Letras, em que se fez uso da tecnologia com vistas a promover uma formação social, crítica e reflexiva do professor. Os dados evidenciaram que o sucesso da atividade não está relacionado diretamente ao uso de uma ferramenta tecnológica apropriada, mas ao engajamento dos participantes na tarefa solicitada, o que implica necessariamente uma nova forma de pensar e agir, (trans)formada e delineada por recursos metodológicos, tecnológicos e contextuais.

- PALAVRAS-CHAVE: Letramento digital. Tecnologia da informação e comunicação. Ferramentas e ambientes digitais. Ensino de língua. Formação contemporânea do professor.

\section{Breves considerações iniciais}

Uma nova e intensa transformação em diversos âmbitos sociais se iniciou com a introdução do grande meio heterogêneo e fronteiriço, denominado por Lévy (1998), de ciberespaço. Esse apresenta características muito peculiares se comparado às demais transformaçóes revolucionárias e de grande impacto, que já ocorreram em nossa sociedade. Tal diferença se justifica, de acordo com o autor, porque não temos mais um espaço vinculado a algo estático, geográfico, institucional ou de Estados, mas, sim, um espaço invisível de conhecimentos e saberes, em que podemos pensar coletivamente e, ainda, influenciá-lo de maneira direta. Resultado de um investimento

\footnotetext{
* UNESP - Universidade Estadual Paulista “Júlio de Mesquita Filho”. Instituto de Biociências, Letras e Ciências Exatas - Departamento de Educação. São José do Rio Preto - SP - Brasil. 15054-000 bedran@ibilce.unesp.br
} 
internacional de jovens que buscam experimentar, coletivamente, formas diferentes e inovadoras de comunicação, o ciberespaço surge da interconexão de computadores e abarca não somente infraestrutura material da comunicação digital como também todas as informaçóes disponíveis e os usuários que navegam e alimentam todo esse universo, conforme aponta Lévy $(1998,1999)$.

Diversos modos de comunicação tornam-se possíveis no ciberespaço diante de recursos da internet que permitem às pessoas interagirem de maneira recíproca, assíncrona e a distância - particularidades inexistentes em outras formas de comunicação até então existentes, como o correio, por exemplo, conforme aponta o autor, e, principalmente, de maneira síncrona, quando pensamos mais contemporaneamente na (re)organização de uma sociedade, a qual se dá a partir da utilização de recursos de áudio e vídeo para e na realização do processo de comunicação. Ao serem responsáveis por novas formas de comunicação, essas inovaçóes tecnológicas necessariamente também contribuem com as novas formas de atuar, de se manifestar, de construir e de se posicionar em sociedade, tendo em vista a particularidade de cada instrumento, aplicativo, plataforma e/ou ambiente tecnológico utilizado, que auxiliam na configuração e delineaçáo dessas diversas práticas. Trata-se, portanto, de novas possibilidades de letramento, se considerarmos o conceito de letramento trazido por Lankshear e Knobel (2006, p. 64) como "modos reconhecidos socialmente de gerar, comunicar e negociar conteúdo significativo" e também por Buzato (2006, p. 5) "[...] uma forma de agir, afirmar-se, construir e sustentar uma visão de mundo partilhada por um grupo."

Em se tratando de práticas já vivenciadas pelos alunos em situações cotidianas, a grande questão incide justamente no trabalho pedagógico de ensino de língua e no processo de formação do professor que sejam desenvolvidos a partir de uma perspectiva situada, que contemple as práticas e os eventos de letramento dos quais os alunos participam em situaçóes extra-ambiente escolar e as ferramentas tecnológicas que possibilitem a realizaçáo e/ou sejam pertinentes para o desenvolvimento de novas práticas de letramento. Nessa abordagem contemporânea de ensino de línguas e de educação do professor, em que se considera o ensino e a aprendizagem como práticas socialmente situadas, o papel do professor, do aluno e o objetivo do ensino e aprendizagem de língua são reconceitualizados a partir de uma concepção crítica, que tem como objetivo promover a conscientização sobre como as relaçóes de poder são construídas (HAWKINS; NORTON, 2009), atrelada a uma perspectiva sociocultural que enfatiza a (re)construção do conhecimento em função do contexto e das relaçóes sociais estabelecidas (VIGOTSKI, 1987, 1999, 2010; JOHNSON, 2009).

Nesse processo, torna-se fundamental uma compreensão de conceitos que também vá ao encontro de uma perspectiva mais contemporânea no que se refere aos estudos do Letramento, que está relacionada a uma concepção social, política e ideológica (STREET, 1995; HAMILTON, 2000; SOARES, 2002; ROJO, 2013). A visão ideológica e social, de acordo com Street (2006, p. 470, apud BEDRAN, 2015, p. 62), leva a "[...] uma pluralidade de letramentos, sujeitos aos contextos sociais, em que se deve ressaltar o 
papel predominante das relações de poder, e que estão, necessariamente, associados a diferentes pessoalidades e identidades [...]", o que significa afirmar que as práticas de leitura e escrita que ensinamos, aprendemos e usamos estáo vinculadas a identidades e a expectativas sociais com relação a comportamentos e papeis desempenhados socialmente (BEDRAN, 2015).

Tendo em vista a necessidade de se repensar a utilização dos recursos tecnológicos no ensino de língua e as (novas) práticas sociais, de forma interdependente, considerando a pluralidade de eventos de letramento, objetivamos, por meio do desenvolvimento deste artigo, instaurar uma discussão sobre o uso da tecnologia da comunicação e informação como responsável por novas práticas de letramento e que pode, portanto, permitir e/ ou instigar a realização de produção escrita, por meio de uma atuação colaborativa (FIGUEIREDO, 2006). Levando-se em consideração a importância fundamental de uma formação adequada e necessária para que o professor possa assumir uma postura crítica e reflexiva (PIMENTA; GHEDIN, 2002; ZEICHNER, 2008) sobre a utilização dos recursos tecnológicos, capaz de torná-lo letrado digitalmente na medida em que ultrapassa a capacidade do domínio meramente técnico, instrumental, da tecnologia em uma determinada situação (BUZATO, 2006, 2009; SAITO; SOUZA, 2011), tencionamos realizar consideraçóes mais pontuais sobre o ambiente Wikispaces, de forma a promover uma reflexão sobre sua utilização em um contexto de formação inicial de professores de língua.

\section{Tecnologia, ensino e colaboração: um convite à discussão}

Os aprendizes da contemporaneidade compartilham informaçóes e conhecimento, a partir do uso de ambientes, ferramentas e aplicativos virtuais, que possibilitam a construção de teias de relacionamento. As novas redes de relaçóes sociais, propiciadas pelas características da Web 2.0, que oferecem mecanismos para comunicação instantânea, agrupam de maneira ágil e abrangente pessoas que tendem a se aproximar por características, objetivos e interesses em comum, compartilhados em comunidades virtuais que rompem barreiras geográficas e temporais e instigam novas oportunidades e possibilidades no processo de produção do conhecimento, conforme apontam Vieira (2008) e Lévy (1998, 1999). Com a Web 2.0, surgem sites de relacionamentos, repositores de vídeos, enciclopédias virtuais, produzidas pelos próprios usuários, ou seja, a internet passa a funcionar como uma plataforma, por meio da qual os usuários podem compartilhar arquivos, vídeos, músicas utilizando aplicativos e ferramentas para essa finalidade.

Enquanto na Web 1.0, os sites funcionavam como folhetos individuais, em que os usuários eram meros expectadores que poderiam, no máximo, realizar downloads do que lhes convinha, na Web 2.0, além do download, usuários realizam upload, participando ativamente de diversas formas. Ao se voltarem especificamente às pesquisas sobre ensino e aprendizagem de língua estrangeria, Sykes, Oskoz e Thorne (2008) evidenciam que a 
Web 2.0 denota um grande potencial ao criar espaços imersivos on-line que possibilitam a aprendizagem de uma segunda língua, e, acrescentamos, espaços propícios para a formação de professores de língua estrangeira e também materna. Conforme o usuário é inserido no sistema, seus arquivos são disponibilizados para todos os outros usuários, potencializando o poder individual de cada participante, que passa a ser produtor e não apenas consumidor de produtos, conhecimento e de informação, o que acarreta consequências no âmbito educacional, uma vez que a internet acaba redesenhando a educação ao criar novas oportunidades de ensino e aprendizagem, podendo ser um forte potencial de transformaçóes em abordagens de ensinar e aprender (VALENTE; MATTAR, 2007; SYKES; OSKOZ; THORNE, 2008).

Lévy (2007), por sua vez, rejeita a ideia de inovação nos conceitos da internet com a Web 2.0. Para o autor, o único fator diferencial é a quantidade de pessoas que se apropriam da tecnologia, o que a torna um fenômeno de massa, mas, do ponto de vista do conceito base, não haveria diferença a ser considerada entre a Web 2.0 e a internet original. Concordamos com o autor que os preceitos base são mantidos - princípios como inteligência coletiva, interconexão e comunidade virtual ${ }^{1}$. Porém, devemos considerá-los como o cerne para o desenvolvimento de outros conceitos mais pontuais quando se pensa em tecnologia e ensino; não podemos deixar de levar em consideração o aprimoramento e o desenvolvimento de novos recursos, instrumentos e plataformas que configuram e delineiam (novas) formas de interação e trazem consequências para o ensino de língua e, também, para o desenvolvimento de pesquisas relacionadas à educação e tecnologia, possibilitando reflexôes e elaboração de conceitos mais recentes, fundamentados em concepçóes já existentes.

Por outro lado, essas inovações tecnológicas, que rapidamente (re)organizam a vida em sociedade e necessitam ser exploradas pedagogicamente, tornam-se desafios para professores e aprendizes no que se refere à seleção cuidadosa das ferramentas para o ensino e aprendizagem de línguas e ao engajamento de professores aprendizes em práticas coletivas de aprendizagem (ABDELRAHEEM, 2003; THORNE; PAYNE, 2005). Nesse difícil processo, há de se observar a existente polarização, não apenas nas práticas e nos eventos de letramento, que podem estar respaldados ou não em formas mais colaborativas e coletivas de aprendizagem, mas, também, nas ferramentas tecnológicas como, por exemplo, a rede social Facebook (BEDRAN; BARBOSA, 2016) e a produção de Fanfictions (AZZARI; CUSTÓDIO, 2013; ALVES; JESUS, 2015). Os eventos mais valorizados academicamente são denominados por Hamilton (2002, p. 4 apud ROJO, 2009) de letramento 'dominante' ou 'institucionalizado' e os letramentos

A interconexão retrata a sociedade em uma comunicação interativa, sem fronteiras e limites geográficos ou temporais. A comunidade virtual baseia-se na interconexão e é construída sobre interesses e afinidades, com base em um processo de cooperação ou troca. Por fim, a inteligência coletiva, que é desenvolvida nas comunidades virtuais por meio da interconexão, refere-se a uma inteligência distribuída por toda parte, coordenada em tempo real, dinâmica e flexível, construída por todos os envolvidos (LÉVY, 1999, p.167). 
locais, dos quais os alunos participam e que são desvalorizados no ambiente formal de ensino, recebem a nomenclatura de 'vernaculares', ou 'autogerado'.

Dentre os recursos que propiciam e instigam o desenvolvimento de formas mais colaborativas de escrita, destacamos o ambiente Wiki. Antes de evidenciarmos suas características e definiçóes, de forma a propiciar uma conscientização sobre sua possibilidade de uso educacional, torna-se fundamental explicitarmos o conceito de prática colaborativa que estamos assumindo neste trabalho. Fundamentadas em uma concepção de colaboraçáo como processo de (co)construçáo de conhecimento realizado pelos participantes a partir de um trabalho conjunto (FIGUEIREDO, 2006; GIBSON; McKAY, 2001; BARBOSA, 2006) e pautadas no modelo sócioconstrututivista do processo de ensino e aprendizagem de línguas de Williams e Burden (1997), Bedran e Barbosa (2016) elaboraram o modelo de prática colaborativa em um processo de formação de professores a partir de uma perspectiva sociocultural, apresentado a seguir.

Figura 1 - O modelo de prática colaborativa em um processo de formação de professores a partir de uma perspectiva sociocultural

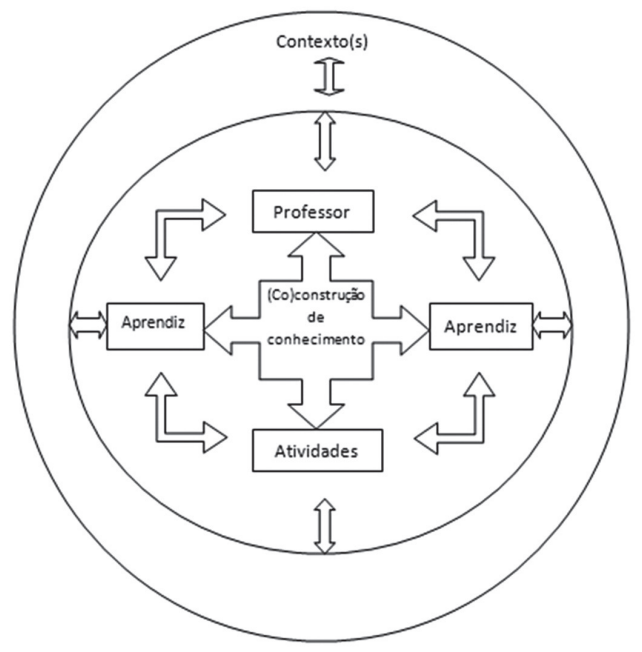

Fonte: Bedran e Barbosa (2016, p. 100).

A formação seria compreendida e realizada sob uma perspectiva sociocultural de ensinar e aprender que une o individual com o social de forma a conceber a aprendizagem como um processo socialmente situado, já que o funcionamento mental do aprendiz não existiria separado da situação cultural, institucional e histórica no qual ele ocorre (JOHNSON, 2009). Na figura, podemos observar que professores e aprendizes interagem e dialogam entre si e com a atividade com vistas à construçấo de 
conhecimento que se dá de maneira negociada e social. Esse processo é influenciado pelo contexto, que também sofre influência da relação entre professores e alunos, atividades e, também, do conhecimento (co)construído. Embora tenha sido pensado para e na formação do professor, entendemos que esse modelo também possa ser adequado e apropriado para o contexto de ensino de língua, além daqueles voltados para a formação profissional. Na definição das autoras (BEDRAN; BARBOSA, 2016, p.100), a colaboração é vista como:

[...] processo de interação social, que se fundamenta em uma perspectiva sociocultural, e tem como fundamento a (co)construção e a (trans)formação de conhecimento, por todos os membros engajados nessa prática, por meio do desenvolvimento de atividades, que tornam-se meio e fim, uma vez que representam tarefas, resolução de problemas e/ou alcance de objetivos diversos e semelhantes que são definidos e realizados por todos os envolvidos em um processo de influências e contribuiçóes múltiplas.

As ferramentas, aplicativos, ambientes e recursos, como Wikis, blogs, chats, áudio, vídeos, sites de relacionamento, entre outros, disponíveis na Web 2.0, compóem a diversidade de mídias tecnológicas que ajudam a constituir o cenário educativo da atualidade e abrem espaços para essas novas práticas pedagógicas, que redefinem a função e a relação entre professores-formadores, professores aprendizes, conteúdos e atividades, indo ao encontro de uma prática pedagógica mais colaborativa. O papel do professor e do aprendiz também é ressignificado - o primeiro tende a desempenhar um papel mais coadjuvante no cenário educativo, abrindo espaço para que o foco incida sobre o aprendiz, o processo de aprendizagem, as relações entre aprendizes e também sobre o conteúdo. Nesse novo cenário, enquanto professores-formadores e/ou professores de língua tornam-se moderadores e/ou mediadores do processo educativo, professores em formação e/ou aprendizes assumem uma postura mais ativa e emancipatória.

A mediação, entendida sob uma perspectiva sociocultural, é condição necessária para que o homem possa interagir com o mundo, pois, de acordo com Vigotski (1999), a relação do homem com o mundo nunca é direta, configurando-se sempre de maneira mediatizada pela linguagem. Quando nos voltamos para o processo de internalização de conceitos no âmbito educacional, a mediação, realizada pelo par mais competente, torna-se de extrema importância para que o processo de (re)construção de conhecimento possa ocorrer da melhor forma possível. Por meio de fornecimento de assistência, denominado por Johnson (2009) de mediação estratégica, o mediador seria responsável por auxiliar o outro no processo de aprendizagem. Nessa mesma perspectiva, corroboramos a definição que Williams e Burden (1997, p. 40 apud BEDRAN; BARBOSA, 2014, p.58, tradução nossa) apresentam para mediação '[...] a parte desempenhada por outras pessoas significantes na vida dos aprendizes que 
estimulem sua aprendizagem por selecionar e moldar as experiências de aprendizagem a eles apresentadas'. ${ }^{2}$

Voltando-nos para a utilização de recursos tecnológicos no âmbito educacional, o processo de mediação do professor, a nosso ver, tem início por meio do posicionamento crítico e reflexivo no momento de compreensão e seleçâo desses recursos, tendo em vista a formação dos alunos que se objetiva alcançar. Essa postura ativa diante da tecnologia, de forma a possibilitar o êxito no desenvolvimento da atividade e da aprendizagem, requer do professor mais do que uma formação técnica, que permite o domínio técnico da ferramenta - exige uma formação reflexiva, questionadora e também produtora diante da tecnologia da informaçáo. Ao trazer o modelo de Multiletramentos Digitais, Selber (2004 apud SAITO; SOUZA, 2011) acredita que os programas corporativos e universitários que objetivam difundir os Letramento(s) Digital(is) o fazem a partir de uma perspectiva autônoma de letramento, ou seja, sem que haja uma abordagem de modo crítico, reflexivo e desejável das relaçôes de poder e dos aspectos ideológicos que subjazem e influenciam o uso da tecnologia.

O modelo de Selber (2004 apud SAITO; SOUZA, 2011) fundamenta-se em três categorias base interdependentes e dinâmicas entre si: Letramento Digital Funcional, Letramento Digital Crítico e Letramento Digital Retórico. No Letramento Funcional, os computadores são vistos como 'ferramentas' e os indivíduos como 'usuários eficientes' dos recursos. Para Saito e Souza (2011, p. 138 e 139), seria o equivalente ao conceito de alfabetização digital, que significa um domínio meramente técnico. Diferentemente do anterior, no Letramento Digital Crítico, o computador seria comparado a 'artefatos culturais' e os indivíduos a 'questionários informados de tecnologia', o que conduziria compreensão de contextos de uso, das forças institucionais que moldam o uso da tecnologia, ou seja, as reflexóes sobre valores, crenças e ideologias subjacentes a essas novas tecnologias. Por fim, no Letramento Digital Retórico, os computadores são como 'mídias digitais' e os indivíduos como 'produtores reflexivos de tecnologia'. Assim como os autores, ressaltamos a importância de tal modelo na análise de cenários variados e de instâncias sociais em que se utiliza a tecnologia da informação e comunicação - dentre eles, ressaltamos o contexto de formação inicial de professores de língua.

Quando há o domínio, não apenas técnico, mas, também, um posicionamento crítico, reflexivo, questionador, com relação ao uso pedagógico de recursos tecnológicos, o professor encontra caminhos para a contemplação, apropriação e /ou desenvolvimento de (novas) práticas letradas, com vistas à sistematização e à obtenção de êxito no processo de aprendizagem com relação à língua ensinada. Nessa perspectiva da pluralidade, ou seja, da multiplicidade e da heterogeneidade de letramentos, há necessidade de se compreender que eles estão, conforme pontua Street (2006, p. 470 apud BEDRAN,

\footnotetext{
2 "[...] refer to the part played by other significant people in the learners' lives, who enhance their learning by selection and shaping the learning experiences presented to them." (BEDRAN; BARBOSA, 2014, p.58).
} 
2015), necessariamente associados a diferentes pessoalidades e identidades, que podem ser identificadas, por exemplo, ao considerarmos a produção textual colaborativa como uma nova prática de letramento. Estamos diante de uma nova concepçáo de texto, de leitor, de autor, de modo de participação para a elaboração da atividade, em um processo que Bruns (2006) denomina de produsagem (produsage) - modo de produção contínuo e colaborativo que torna usuários produtores - use-produser - de conhecimento e informação. Essa nova forma de produção, que traz consequências no âmbito educacional, na medida em que (trans)forma a maneira como se compreende o ensino, a atividade, e os papéis dos participantes, tende a ser possibilitado e/ou instigado por recursos tecnológicos que apresentam uma arquitetura voltada para esse tipo de trabalho.

\section{Tecnologia Wiki}

A tecnologia Wiki cria a possibilidade de autoria colaborativa e de produçóes textuais elaboradas, que resultam em recursos como a Wikipédia (WARSCHAUER; LIAW, 2010). Faz-se necessário explicitar que, ao nos referirmos à "tecnologia Wiki", estamos fazendo menção a um tipo específico de coleção de documentos em hipertexto. Para nos reportarmos ao recurso tecnológico utilizado, ou melhor, à ferramenta, empregaremos o termo "recurso Wiki" ou "ambiente Wiki". Entendemos que esses dois termos possam ser tomados como sinônimos, porém, há de nos atentarmos para o fato de que o segundo, "ambiente de aprendizagem", nos remete à ideia mais ampla, ou seja, de desenvolvimento de condições para a aprendizagem, não só por meio de recursos tecnológicos, mas, também, outros como recursos humanos e metodológicos, advindos da mediação do par mais competente.

Inventado por Ward Cunningham em 1995 com o projeto chamado Portland Pattern Repository (site de programação de computadores), o termo Wiki vem do havaiano wiki wiki e significa rápido. Inicialmente utilizado por programadores de computadores e planejadores de sistemas, Wikis passam a se tornar um ambiente viável para a colaboração e a comunicação (SYKES; OSKOZ; THORNE, 2008; THORNE; PAYNE, 2005). Apresentam como filosofia base um sistema de desenvolvimento de diversas habilidades, como a leitura e a escrita, e são definidos como websites sobre os quais o usuário pode contribuir com a produção de textos. Ao editar nesses sites, usuários escrevem e reescrevem qualquer texto e contribuem para a produção de uma obra textual de interesse comum, por meio da sustentação de forças humanas intelectuais e colaborativas que lhes permitem contribuir com ideias, percepçóes e pensamentos compartilhados (VIEIRA, 2008; WARSCHAUER; LIAW, 2010).

Um dos recursos produzidos pela Wiki é a Wikipédia, um dos dez sites mais visitados do mundo, que abarca mais de 250 línguas. Os contribuintes ativos da Wikipédia, por meio da escrita colaborativa, transformam o caminho pelo qual o conhecimento é produzido e documentado (SYKES; OSKOZ; THORNE, 2008; WARSCHAUER; 
LIAW, 2010). Dificilmente encontra-se um usuário que não esteja familirizado com a Wikipédia e muitas das discussóes giram em torno de sua credibilidade como fonte para pesquisas, o que, a nosso ver, não deixa de ter um valor positivo porque aumenta ainda mais a autonomia e a responsabilidade dos aprendizes no processo de avaliaçáo das informaçóes encontradas.

Citado no Warschauer e Liaw (2010, p. 7), o inventor da tecnologia Wiki afirma que "[...] a blogosfera é a comunidade que produz um trabalho, já uma Wiki é um trabalho que deve produzir uma comunidade." 3 Trata-se de um meio propício para explorar identidades, falar de si próprio, apresentar diversas visóes e desenvolver comunidades, mas que ainda se depara com muitos obstáculos, como a dificuldade de tomar decisōes em grupo que estáo separados por espaço e tempo. Ao pensarmos na sua utilizaçáo pedagógica, acreditamos que a dificuldade vai além da habilidade e capacidade de tomar decisóes, incidindo, de maneira mais profunda, sobre o processo de se construir um texto, a muitas mãos, uma vez que modelos tradicionais de ensino e aprendizagem ainda se centram na produção individual, amparados, muitas vezes, pelas ideias competitivas, arraigadas em nossa sociedade, o que geralmente ocasionam a realização de trabalho cooperativo e não colaborativo.

Por outro lado, há vantagens nesse tipo de tecnologia e em outros ambientes tecnológicos colaborativos on-line, como apontados por Vieira (2008), as quais motivam a sua utilização como, por exemplo, a facilidade de acesso, a interação, a partilha de conhecimento, a atualidade, a gratuidade, entre outros. Nas comunidades virtuais, os participantes tornam-se mais ativos e responsáveis nas trocas de experiências e no auxílio mútuo, o que é visto pela autora como vantagem e motivação. Porém, em termos pedagógicos, há necessidade de preparar professores para essa nova realidade e também os próprios aprendizes que, ao invés de motivados, podem apresentar, muitas vezes, rejeição inicial a esse novo ambiente de aprendizagem ou, então, fazer um uso descritivo e exploratório de um Wiki em sala de aula, conforme mostram Thorne e Payne (2005).

Diferente de aplicaçóes descritivas ou exploratórias, inovados usos de Wikis têm sido apontados por pesquisas, de acordo com Sykes, Oskoz e Thorne (2008). Há utilização para conectar classes de metodologia entre universidades (LOMICKA; LORD; DUCATE; ARNOLD, 2007 apud SYKES; OSKOZ; THORNE, 2008), para avaliar o conteúdo dos estudantes e o desenvolvimento de redação (OSKOZ; ELOLA, 2008 apud SYKES; OSKOZ; THORNE, 2008) e para avaliar o uso da língua dos aprendizes (KOST, 2007 apud SYKES; OSKOZ; THORNE, 2008). De acordo Sykes, Oskoz e Thorne (2008), surgem, desses estudos e da literatura geral sobre Wiki, duas atribuições a serem consideradas: a reconceitualização da autoria e as mudanças para abordar o processo de escrita como um todo, o que suscita, a nosso ver, reformulaçáo

\footnotetext{
3 "[...] the blogosphere is a community that might produce a work, whereas a wiki is a work that might produce a community."
} 
no processo de formação de professores para lidar com essa nova realidade e trabalhála em sala de aula.

Thorne e Payne (2005) também fazem menção à problematização da autoria. De acordo com os autores, páginas individuais, e aqui talvez possamos fazer menção ao Wikispaces, podem ser limitadas para um grupo de usuários e todos que a utilizam e têm acesso podem contribuir produzindo textos e tornando-se, dessa forma, autores de arquivos que estão constantemente sendo reformulados e que não são demarcados pela individualidade, mas, sim, pelo trabalho coletivo. Por outro lado, o Wikipaces deixa rastros de cada adição, apagamento ou modificação realizada pelos usuários, o que pode ser um fator positivo, a depender do intuito do organizador do Wiki, e contribuir com avaliaçóes por parte dos instrutores, quando pensamos no âmbito pedagógico, pois, dessa forma, eles conseguem identificar quem participa, como participa e com que frequência.

A pesquisa realizada por Vieira (2008) mostra características do ambiente Wiki, as quais são agrupadas em pontos fortes e fracos: é de fácil acesso, uma forma alternativa de estudo, promove interaçóes entre turmas, partilha de conhecimento e há uma constante preocupação dos alunos em expor informaçóes coerentes, além de apresentar fácil recuperação de senha. Por outro lado, apresenta alguns pontos fracos, como a impossibilidade de postagens simultâneas, falta de padronização na formataçáo de textos, falta de interesse dos alunos, pouca divulgaçáo ou socialização e fácil alteração de postagens, que está relacionada à credibilidade e à necessidade do trabalho colaborativo, requerendo a participação e o comprometimento dos envolvidos para uma construção textual colaborativa, o que, a nosso ver, trata-se também de uma qualidade, um fator positivo, embora compreendamos que, talvez pela dificuldade dos aprendizes em trabalhar colaborativamente, essa característica seja apontada como um ponto fraco pela autora.

A organização WikiMatrix lista mais de 100 diferentes tipos de Wikis diferentes e permite que você as compare com base em várias características. De acordo com estatística apresentada pela Wikimatrix, o número aproximado de Wikipasces é de um milhão e meio, totalizando em torno de quatro milhóes de usuários no mundo todo, e apresenta oito línguas de interface. Ao fazer a inscrição, os usuários recebem um subdomínio em wikispaces.com - versão gratuita suportada por anúncios do Google. Não há limites sobre o número de páginas, espaços ou membros e há versões gratuitas e também pagas. O público-alvo principal constitui-se de membros de grupo de interesse, da área educacional e de pequenas empresas. Por apresentar tantos usuários, inclusive no âmbito educacional, mas, de certa forma, ainda ser raramente usado em contextos de ensino no Brasil e pouco investigado pelas pesquisas na área, optamos por esse ambiente em detrimento a outros Wikis. Além disso, apresentamos, ainda como justificativa, a questâo da facilidade técnica de uso dessa ferramenta.

4 Disponível em: <www.wikimatrix.org>. Acesso em: 26 set. 2016. 


\section{Tecendo considerações a respeito do uso do Wikispaces em um contexto de formação de professores}

Pautando-nos na definição de estudo de caso de André (2005) - estudo exaustivo de um caso ou descritivo de uma unidade - entendemos que esta pesquisa, além de ser qualitativa de cunho etnográfico (ERICKSON, 1986; ANDRÉ, 2000), se configura, ainda, como um estudo de caso, porque investiga a utilização do Wikispaces em um contexto específico de formação inicial de professores no e para o meio virtual, com um número limitado de participantes. Os participantes focais são Antonia Maria, Antonio Jorge, Charlote e João, alunos do curso de Licenciatura em Letras de uma universidade pública, localizada no estado de São Paulo, e a professora-formadora mediadora, Flávia - todos nomes fictícios. Como instrumentos para coleta de dados, foram utilizados, além do registro no ambiente Wikispaces, uma entrevista semiestruturada com os participantes e o registro de diálogos entre professora formadora e pesquisadora.

O contexto mais amplo em que a presente pesquisa está inserida é o Tetetandem (ttandem). Concebido como uma alternativa ou complementação da aprendizagem de língua estrangeira em contextos típicos e presenciais, o ttandem assume uma concepção de troca, de trabalho colaborativo em meio virtual a partir da utilização de webcan e remete à ideia, a priori, da bicicleta tandem, em que duas pessoas realizam um trabalho mútuo e coletivo, pedalando, juntas, para atingirem um mesmo objetivo Brammerts (2002) e Telles e Vassallo (2006). Nesta pesquisa, o ttandem foi realizado de maneira independente do contexto de sala de aula e com sessôes de mediação, também denominadas de aconselhamento (VASSALLO; TELLES, 2006, 2009a, 2009b; TELLES, 2009; BENEDETTI; CONSOLO; VIEIRA-ABRAHÃO, 2010).

As sessóes de mediação, pautadas nas quinze diretrizes do mediador ${ }^{5}$, fundamentadas em uma perspectiva sociocultural de ensino, realizadas pela professora formadora e mediadora Flávia, tinham como principal objetivo auxiliar a formação dos futuros professores por meio do desenvolvimento de um processo reflexivo e colaborativo entre os participantes, tendo em vista as dificuldades enfrentadas pelos professores em formação inicial durante a realização da sessão de ttandem. Nessas sessões de ttandem, os participantes desta pesquisa, futuros professores, denominados também de interagentes, engajavam-se em um trabalho colaborativo com os interagentes italianos, para que um pudesse aprender a língua do outro. As sessóes de ttandem, de acordo com Telles e Vassallo (2006), deveriam ser de duas horas, uma para cada língua (feitas no mesmo dia, ou em dias separados), sendo cada hora composta das seguintes fases: conversação sobre um ou vários assuntos (cerca de 30 minutos); feedback linguístico (cerca de 20 minutos); e reflexão compartilhada na sessão (aproximadamente 10 minutos).

Nesta pesquisa buscamos tecer considerações acerca da utilização do ambiente Wikispaces para o desenvolvimento de atividades que complementavam as sessóes de

Confira TELETANDEM NEWS (2006, p.7). 
mediaçóes que foram realizadas de forma presencial e também virtual, por meio de ferramentas que permitiam interaçóes síncronas com todos os participantes. Assumindo a concepçáo de Wiki como uma possibilidade de espaço para a construção colaborativa de textos, por meio de uma participação ativa, crítica e reflexiva, o objetivo da atividade era possibilitar a leitura e a construção de textos, que traziam conteúdos de interesse dos professores em formação, uma vez selecionados a partir de questóes e dificuldades enfrentadas em suas respectivas sessóes de ttandem e que haviam sido discutidas durante as sessóes síncronas de mediação.

Diante da importância da familiarização e do domínio técnico da ferramenta (SAITO; SOUZA, 2011), no início do trabalho com o ambiente Wikispaces, foi realizada uma reuniáo com os professores em formação e a mediadora para que juntos eles pudessem aprender a base de funcionamento desse novo ambiente, uma vez que se tratava de um recurso tecnológico novo para todos. Apesar de a mediadora considerar o Wikispaces um espaço de todos e tentar abordá-lo como um ambiente em que os participantes poderiam fazer suas contribuiçóes, da maneira como desejassem, a partir do encorajamento de participaçáo em múltiplos discursos, fazendo uso de uma abordagem de participação coletiva (SINGH; RICHARD, 2009), os professores em formação não participaram ativamente das atividades.

$\mathrm{Na}$ tentativa de compreender o insucesso do uso do Wikispaces para realização das atividades propostas, destacamos, primeiramente, os recursos metodológicos utilizados pela formadora. No primeiro excerto (linhas 2 e 3 ), visualizamos a tentativa da professora de deixar os professores em formação à vontade para postarem observaçóes e reflexóes sobre o texto sugerido e postado no link "sugestóes", os quais apresentavam temas abordados nas mediaçóes regulares (reunióes síncronas). Em seguida (excerto 2, da linha 3 a 5), podemos identificar como procedimento da mediadora a introdução um pequeno texto com seus comentários e reflexóes acerca da teoria, apresentada no vídeo proposto no link "sugestóes" e também abordada em reunião regular de mediação, e, posteriormente, a introduçáo de questionamentos para que os professores-aprendizes dessem continuidade ao texto (excerto 2 , da linha 3 a 5 ).

\section{Excerto 1}

1.Bom, a primeira sugestão que eu gostaria de fazer é a leitura de um texto sobre o feedback em ambiente 2.virtual (http://www.veramenezes.com/feedback.htm). Acho que será bastante útil... Dêem uma olhada no 3.texto e postem suas observações...e eu adoraria discutir as questões que vocêss acharem interessantes. (Registro da professora-mediadora - Wikispaces)

\section{Excerto 2}

1.Toda vez que leio um texto sobre o uso da tecnologia com fins pedagógicos fico surpresa com o quão pouco 2.estamos fazendo. Fico mais surpresa ainda por que os alunos estão, em geral, imersos na tecnologia, mas ela 3.nem sempre está presente na sala de aula da maneira como está presente na vida de cada um deles. Será que os 4.professores não sabem utilizar a tecnologia de maneira didática? VCs também têm essa impressão? Vcs vêem 5.o ambiente teletandem como uma oportunidade de uso pedagógico das ferramentas tecnológicas? (Registro da professora-mediadora - Wikispaces) 
Os comentários e as respostas às questóes propostas pela mediadora eram realizados prioritariamente por uma das participantes, Antonia Maria. Por outro lado, é importante ressaltar que a falta de postagens não significa que os professores em formação não haviam realizado a leitura solicitada. Antonio Jorge, por exemplo, quando questionado sobre a importância das atividades para sua formação, conforme mostra o excerto que segue, declara terem sido úteis os textos do Wikispaces para sua reflexão (excerto 3), porém, não há postagens suas nesse ambiente.

\section{Excerto 3}

1. (...) pelo Wiki refleti sobre os textos postados, nas mediações refleti sobre os depoimentos dos meus colegas (...) (Entrevista com Antonio Jorge)

Uma possível justificativa para a falta de postagens e a dificuldade de produçáo colaborativa pode estar associada à maneira como a mediadora estava solicitando as atividades. A formadora chega à conclusão que as instruçóes dadas por ela poderiam não estar condizentes com aquilo que realmente ela esperava dos professores em formação. Em conversa informal com a pesquisadora, Flávia comenta que postou um texto sobre autonomia e que mudaria a instrução para a realização da atividade. Os questionamentos e/ou a instrução "faça seu comentário" seriam substituídos pela instrução "continue a ideia". A mudança no enunciado, que apresentava instruçóes sobre como proceder, tinha como objetivo fazer com que os professores-aprendizes não postassem comentários fragmentados, mas construíssem um só texto, como mostra o excerto 4.

\section{Excerto 4}

1.Flávia: se ninguém postar nada até quinta, vou postar um comentário sobre meu próprio texto e enviar outro

2.e-mail pra eles

3.Pesquisadora: então, isso que eu queria ver com você, talvez eles precisem de um "modelo"

4.Flávia: sim, conforme conversamos outro dia...acho que a instrução agora deve ser "continue essa ideia"

5.(...)

6.Flávia: porque fazer comentários pode dar a entender que eles devem postar em um parágrafo separado e 7.gostaríamos que eles continuassem o texto....o que vc acha?

8.Pesquisadora: Realmente...essa é a ideia....mas não poderíamos colocar "escreva um texto", "dê continuidade 9.ao texto", logo no início porque isto é difícil para eles...escrever a muitas mãos é difícil, mas acho que chegou 10.a hora de sermos mais diretas...mas não vai adiantar ser direta e não ter um modelo...(Registro de conversa 11.informal por chat entre Flávia e a Pesquisadora)

A apresentação inicial de um modelo para que os aprendizes entendessem o funcionamento do Wikispaces, mencionada pela pesquisadora (excerto 4, linha 3), também poderia ter facilitado a compreensão do funcionamento do mesmo e a realização do objetivo proposto. Porém, somente na penúltima mediação, Flávia, ao sentir essa necessidade, apresenta um modelo de um Wiki que havia sido bem sucedido. $\mathrm{O}$ Wikispaces em questão foi utilizado pelos alunos de pós-graduação de uma universidade pública paulista, na disciplina Tópicos Especiais de Linguística Aplicada: A formação do formador e do professor de língua estrangeira. Ao apresentá-lo, a formadora discute a 
prática colaborativa de produção e elenca algumas considerações sobre o processo de construção desse texto, classificando o gênero textual que foi elaborado pelos alunos como resumo, como mostra o excerto que segue.

\section{Excerto 5}

1.Flávia: olha só aqui os alunos são acho que 17 ou 18 alunos eles leram esses dois textos aqui né? os dois links 2. $(+)$ e aí cada um escreveu alguma coisa/escreveu alguma coisa pra: resumir as ideias principais do texto só 3.que como vocês tão vendo não são 17 pequenos resumos $(+)$ conforme as pessoas vão adicionando suas 4.ideias contribuindo com alguma ideia diferente elas vão adaptando o texto que já estava pra que o texto final 5.fique sendo assim uma amostra da ideia de todo mun/das ideias de todo mundo mas formando um texto só 6.né? com coesão coerência com colaboração de todo mundo

7.Antonio Jorge: uhum

8.Flávia: então muitas vezes você tem um marcador textual do tipo porém por outro lado além disso etc mudar 9.o tempo verbal que a pessoa estava escrevendo o texto estava utilizando mas que não faz sentido você 10.continuar então às vezes você vai ter que mudar o texto anterior pra adaptar as ideias que você tem que 11.incluir porque a proposta é que o texto final seja de fato uma colaboração de todo mundo e que não fique é 12.uma colcha de retalhos mas você não percebe as emendas tá vendo?

13. Charlotte: certo

14.Antonio Jorge: é verdade parece um texto feito por uma pessoa só

15.Flávia: exato e foram 17 alunos que escreveram não sei se são 17 eu não me lembro exatamente quantos 16.aham ((contando número de participantes)) 13 são 13 participantes oh: quer ver abram numa outra aula por 17. exemplo.a aula cinco ((todos acessam a aula 5)) ( $6^{\mathrm{a}}$ mediação Virtual Síncrona)

Nessa perspectiva, destacamos a importância de definir um gênero textual no momento da escrita colaborativa e também de se trabalhar as condiçóes de produção desse gênero (DOLZ; SCHNEUWLY, 2004; SANTOS et al., 2007), uma vez que o objetivo da atividade era instigar a produção textual, para que conceitos científicos pudessem ser introduzidos, discutidos e construídos. Os professores possivelmente compreenderam o propósito de atividade, mas podem ter apresentado dificuldade para compreender como isso deveria ser viabilizado e qual gênero deveria ser contemplado. Percebe-se, assim, que o eixo estruturante é a prática social, indo ao encontro de uma perspectiva do Letramento (ROJO, 2013), porém, as estratégias e conteúdos necessários, embora não sejam ou devam ser o ponto de partida, tornam-se fundamentais na realização desse tipo de atividade, conforme pontua Kleiman (2008), ao abordar questôes referentes ao letramento e ao ensino de língua materna, que, a nosso ver, podem e devem ser estendidas para o contexto de formação de língua estrangeira.

Após intensa reflexão e discussão com a pesquisadora, em uma futura atividade, a mediadora muda a estratégia - inicia a construção do texto e sugere para os participantes darem continuidade ao parágrafo iniciado por ela. A tentativa é tímida, apenas um parágrafo é escrito, posteriormente, por uma das participantes, os demais náo participam. A professora em formação, Antônia Maria, tenta se desvencilhar da marca subjetiva no sentido de uma participação despersonalizada (WARSCHAUER; LIAW, 2010), que fica visível apenas para o administrador, no caso pesquisadora e formadora, as quais tem acesso ao histórico do Wikispaces e, assim, conseguem identificar que foi essa participante que contribuiu e deu prosseguimento ao texto. No excerto que segue, podemos visualizar 
o parágrafo escrito por Antonia Maria (da linha 5 a 8) e pela mediadora que iniciou a atividade (da linha 1 a 4 ).

Com exceção dessa participação tímida, a escrita colaborativa não obteve maior êxito. Há de se considerar, também, que esse foi o penúltimo texto postado pela mediadora, porque as reuniôes de mediação estavam sendo finalizadas. Os participantes ainda continuaram fazendo parte do Wikispaces, porém não havia mais o compromisso com reunióes de mediaçóes e postagens de textos.

\section{$\underline{\text { Excerto } 6}$}

1.Nesse texto, Paiva apresenta sugestões práticas para que o professor de língua estrangeira possa lidar, em 2.sala de aula, com o desafio de ensinar a língua e, ao mesmo tempo, ajudar o aprendiz no exercício de sua 3.autonomia, o que envolve aspectos do gerenciamento da aprendizagem, como: estabelecimento de metas, 4.busca de estratégias, avaliação do progresso etc..((postado por Flávia))

5.Temos que refletir sobre o papel do professor, um ensino não pode ser passivo, os alunos precisam participar 6.e se sentirem agentes. É como numa interação de teletandem, quando é a nossa vez de ensinarmos não 7.podemos tomar todo o espaço de uma interação, e nossa interagente que fale depois. O próprio verbo 8.interagir, pede uma via de mão dupla ((postado por Antonia Maria)) (Wikispaces - identificação dos autores pela pesquisadora)

Além da estratégia e dos procedimentos utilizados pela formadora, podemos também sinalizar o fator intimidador da escrita como possível responsável pelo insucesso da prática colaborativa. $\mathrm{Na}$ concepçáo da professora mediadora, a dificuldade do professor em formação estaria associada ao fato de os textos escritos ficarem registrados de maneira permanente, tanto o que se faz corretamente quanto o que se faz de maneira inadequada (excerto 7, da linha 1 a 3). Assim sendo, a dificuldade estaria em expor suas falhas. Por outro lado, quando a mediação era realizada de forma síncrona, a compreensão seria facilitada porque todos estariam presentes em uma relação dinâmica, podendo esclarecer quaisquer dúvidas em curto prazo e os momentos de dúvidas ou "ignorância”, conforme menciona a mediadora Flávia, acabam sendo diluídos em meio a toda uma discussão mais ampla (da linha 3 a 6 ).

\section{Excerto 7}

1.Flávia: mas acho que o registro é algo intimidador, todo mundo pode ter (pelo resto da vida) o que você fez e 2.ninguém gosta de ver suas falhas expostas. Tudo bem que não tem certo e errado, mas acho que eles se sentem 3.julgados por mim (e até por vc) quando eu coloco algum questionamento por escrito, veja bem, quando a gente 4.tá falando e percebe que o que dizemos não está bem de acordo com o que a profa/orientadora acha a gente 5.procura entender o que ela quer, fazer perguntas, se justifica e isso se perde. Ninguém fica visitando aquele seu 6.momento de "ignorância" (Registro da conversa informal por chat entre Flávia e a pesquisadora)

O fator de intimidação da escrita, mencionado por Flávia, pode ser intensificado quando a produção é realizada de maneira colaborativa. Essa nova forma de agir, de se sustentar, de construir e de se comunicar é o que a sociedade espera do educando em sua vida social. Por outro lado, o que predomina nos contextos de ensino, de acordo 
com Bruns (2006), ainda é uma prática hierárquica, condutora e autodeterminada que, consequentemente, traz como resultados trabalhos efêmeros para serem avaliados pelo professor e, a nosso ver, pode gerar resistência, a priori, a outras formas de aprender. Essa nova prática, denominada por Bruns de produsagem, implica uma nova abordagem no que diz respeito à propriedade intelectual, à avaliaçáo da produçáo e dos participantes, aos papéis dos participantes, que se tornam mais fluidos e à relação entre eles, que se torna menos hierárquica, conforme pontua o autor.

$\mathrm{Na}$ condição de produsuário, cabe ao participante, não apenas o papel de um leitor e escritor, conforme pontua o autor, mas, também, a nosso ver, de mediador do processo (BEDRAN, 2015). Em uma relação que se dá forma menos hierárquica, o texto passa a ser concebido como um constructo passível de revisóes e de (re) elaboraçóes e todos, juntamente com o professor-mediador, seriam responsáveis pelo processo e pela criaçáo de condiçóes necessárias e adequadas para que a atividade seja realizada. O processo, que aparentemente seria simples, exige o que Maia (2009) chama de novo ethos, ao se referir ao letramento digital, pois, para o autor, letramento que contempla alta tecnologia envolve, obrigatoriamente, a apropriação de uma nova forma de ação.

Atrelados à necessidade e à dificuldade de (des)construção de concepçóes, formas de posicionamento e de ação, estão a questão do tempo e a prioridade de tarefas no processo de formação do professor. A seguir, os excertos mostram que Antonio Jorge e Antonia Maria alegaram falta de tempo para a leitura de textos e a elaboração da escrita e Antonia Maria atentou-se para a questão de prioridade de tarefas. Para ela, o tempo é escasso e as leituras dos textos das disciplinas do currículo deveriam ser consideradas como mais relevantes, talvez porque faziam parte do programa da universidade e porque havia uma avaliação formal, diferentemente das sessôes e das atividades de ttandem, que não estavam vinculadas a nenhuma disciplina ou ao programa curricular do curso de graduação.

\section{Excerto 8}

1.Antonio Jorge:

2.Olha, eu acho que a participação no wiki requer um tempo que eu não tinha. As atividades do wiki por mais

3.que parecessem interessantes eram um pouco cansativas também, mas falo isso por mim.(Entrevista)

\section{Excerto 9}

\section{Antonia Maria:}

2.o que acontece também é a questão do tempo

3.por exemplo, para se ler um texto do wiki e comentar era necessário no mínimo 1 hora.

4.nesse mesmo tempo podíamos ler um outro texto de uma disciplina da faculdade ou adiantar algum trabalho (Entrevista) 
A falta de obrigatoriedade do Wikispaces não se restringia apenas ao vínculo com as disciplinas da universidade e sua avaliação. Havia uma falta de obrigatoriedade, que contribuiu para a ausência da participação dos envolvidos, associada à assincronia e à atemporalidade, características desse ambiente, como mostra o excerto que segue. $\mathrm{O}$ comprometimento com o ambiente talvez fosse menor, de acordo com o participante, porque, diferentemente das mediaçóes regulares e síncronas, a participação poderia ser realizada a qualquer momento ou mesmo não ser realizada, devido à junção do caráter assíncrono e atemporal do ambiente. Isso comprometeria de forma menos intensa, pelo menos de maneira imediatista, o desenvolvimento da comunidade e do trabalho colaborativo. É diferente do que ocorre com as reuniôes presenciais ou as realizadas por videconferência e chat, as quais, por serem síncronas, com horário determinado, a ausência dos participantes comprometeria o desenvolvimento da atividade em questão.

\section{Excerto 10}

1.Pesquisadora:

2.hum....

3.e por que você acha que os demais participantes não participavam tanto do wiki?

4.Antonio Jorge:

5.acredito pelo wiki não ter um caráter "obrigatório" onde deveríamos estar presentes...

6.Pesquisadora:

7.diferente da reunião de mediação, né?

8.Antonio Jorge:

9.as mediações tinham um caráter de uma reunião onde a falta de um participante compromete incisivamente 10.aquele encontro

11.uhum

12.diferente

13.Pesquisadora:

14.então pensando no grupo, em todos....as pessoas participavam, já no wiki, um não depende tanto do outro 15.(pelo menos à priori...ou superficialmente) e a falta daquele participante não compromete todo o processo...é 16.isso?

17.Antonio Jorge:

18. exatamente

19.é claro que a falta de participantes no wiki compromete o processo, mas não na mesma "proporção" do que se 20.comprometeria em uma mediação

21.é bem o que você disse mesmo

22. ao utilizar o termo "a priori"(Entrevista)

Nesta pesquisa, o Wikispaces não se configurou como um ambiente de construção textual colaborativa e de trocas significativas entre os participantes. Os fatores que possivelmente explicariam a falta de engajamento dos participantes são: possível intervenção inicial e procedimentos realizados de maneira inapropriada pela mediadora; características do próprio ambiente assíncrono e atemporal; falta de tempo dos professores-aprendizes e exigência de tempo maior para a elaboração escrita, devido a sua complexidade; escrita como fator intimidador; prioridade dada às atividades que deveriam ser avaliadas nas disciplinas do curso universitário e, ainda, falta de maior familiarização e experiência com o ambiente Wiki. 


\section{Considerações Finais}

Por meio do desenvolvimento desta pesquisa, foi possível promover uma discussão sobre o uso da tecnologia da comunicação e da informação no âmbito educacional. $\mathrm{Na}$ tentativa de contemplar e repensar a formação do professor sob um viés mais contemporâneo, nos voltarmos para a compreensão de conceitos como colaboração, perspectiva sociocultural e letramento digital no ensino. Ao buscarmos estabelecer uma articulação entre os conceitos, evidenciamos a possibilidade dos recursos tecnológicos, oriundos da Web 2.0, propiciarem a realização de uma prática colaborativa, tendo em vista uma formação pautada em uma perspectiva sociocultural, que evidencia o aspecto social como mecanismo imprescindível para o desenvolvimento cognitivo e social do indíviduo-aprendiz Vigotski (1998, 2010) e Friedrich (2012).

Os dados analisados, coletados em um contexto de formação inicial de professores de língua, em que se tentou desenvolver uma atividade de produção textual no ambiente Wikispaces, evidenciaram que o sucesso da atividade não está relacionado diretamente à tecnologia apropriada, mas ao engajamento dos participantes na tarefa solicitada, que é influenciado e delineado por recursos tecnológicos, metodológicos e fatores contextuais, ou seja, pelo procedimento do professor, características do próprio ambiente, exigência temporal, prioridade e obrigatoriedade de tarefas, escrita como fator intimidador e familiarização com o recurso. Explorar tecnicamente o ambiente e utilizálo pedagogicamente, tendo em vista que os letramentos eletrônicos, conforme pontua Saito e Souza (2011) envolvem usos e práticas discursivas relacionadas ao computador, que estấo embasados em novos padróes internacionais, nova linguagem e novos gêneros do discurso, tornaram-se um grande desafio para a formadora e os professores-aprendizes investigados.

Nesse desafio, ressaltamos a necessidade de um real engajamento dos professoresaprendizes com a atividade e com os demais participantes, ou, conforme pontua Wenger (1998) ao abordar o conceito de Comunidade de Prática ${ }^{6}$, uma participação ativa na prática e na construção de uma identidade em relação à dada comunidade, o que modifica, não apenas o que fazemos, mas, também, quem somos e como interpretamos o que fazemos. Para o autor, a aprendizagem, vista como necessariamente um fenômeno social, desenvolve-se por meio da participação, que não se refere apenas a engajamento, mas a uma atuação ativa, que, a nosso ver, converge com as consideraçóes trazidas por Maia (2009) ao se referir à relação indissociável entre a tecnologia e um novo ethos.

\footnotetext{
6 "Comunidades de prática são grupos de pessoas que compartilham um assunto ou uma paixão por algo que eles fazem e aprendem como fazer isto melhor quando interagem regularmente." (WENGER, 2006, tradução nossa).

"Communities of practice are groups of people who share a concern or a passion for something they do and learn how to do it better as they interact regularly." (WENGER, 2006, original).
} 


\section{DIGITAL LITERACY AND LANGUAGE TEACHER EDUCATION IN CONTEMPORARY TIMES}

- ABSTRACT: In an attempt to consider and rethink teacher education in a more contemporary perspective, we aim to promote a discussion on the use of information and communication technology (LEVY, 1998; 1999; 2007) as responsible for (new) literacy practices within education from the reflection and articulation of concepts and perspectives on Digital Literacy (STREET, 1995; BUZATO, 2006; ROJO, 2013) and Sociocultural Education Teacher (VIGOTSKI, 1998; 2010; JOHNSON, 2009; FRIEDRICH, 2012). In order to instigate a reflection on practical experience in the light of this literature, we weave more specific considerations of a qualitative and ethnographic research in an initial teacher education context, which made use of technology aiming at a social, critical and reflective construction of these teachers. The data showed that the success of the activity is not directly related to the use of appropriate technology but to the engagement of the participants in the requested task, which implies a new way of thinking and acting.

- KEYWORDS: Digital literacy. Technology of information and communication. Tools and digital environments. Language teaching. Contemporary teacher education.

\section{REFERÊNCIAS}

ABDELRAHEEM, A. Y. Computerized learning environments: problems, design challenges and future promises. The Journal of Interactive Online Learning, [S.1.], v. 2, n. 2, p.01-09, 2003.

ALVES, E. C. A.; JESUS, D. M. Fanfiction: estudo sobre práticas de letramento de adolescentes na internet. Norte@mentos, Sinop, v. 8, n. 16, p. 223-238, jul./dez. 2015.

ANDRÉ, M. E. D. A. Estudo de caso em pesquisa e avaliaçáo educacional. Brasília: Liber Livro, 2005.

ANDRÉ, M. E. D. A. Etnografia da prática escolar. 4. ed. Campinas: Papires, 2000.

AZZARI, E. F.; CUSTÓDIO, M. A. Fanfics, Google Docs... a produção textual colaborativa. In: ROJO, H. R. et al. (Org.). Esc@la conectada: os multiletramentos e as TICs. São Paulo: Parábola, 2013. p.73-109.

BARBOSA, A. E. T. Ambientes de aprendizagem de curso on-line e desenvolvimento de pensamento crítico. Estudos Linguísticos, São Paulo, v.XXXV, p. 392-401, 2006.

BEDRAN, P. F. A escrita colaborativa em um contexto de formação de professores de língua. Raído, Dourados, v. 9, n. 18, p. 59-84, 2015. Disponível em: <http://ojs.ws.ufgd.edu.br/index. php?journal=Raido\&page=article\&op=view\&path\%5B\%5D=3944\&path\%5B\%5D=22044>. Acesso em: 13 set. 2015. 
BEDRAN, P. F.; BARBOSA, S. M. A. D. Prática colaborativa: concepções e reflexões a partir de uma perspectiva sociocultural. Domínios da Lingu@gem, Uberlândia, v. 10, n. 1, p.89-120, 2016.

BEDRAN, P. F.; BARBOSA, S. M. A. D. Diários reflexivos: contribuição na (Re)significação acerca da mediação em aprendizagem virtual de língua. Contexturas, [Sáo Paulo], n. 22, p. 49-78, 2014.

BENEDETTI, A. M.; CONSOlO, D. A.; VIEIRA-ABRAHÃO, M. H. Pesquisas em ensino e aprendizagem no teletandem Brasil: línguas estrangeiras para todos. Campinas: Pontes, 2010.

BRAMMERTS, H. Aprendizagem autônoma de línguas em tandem: desenvolvimento de um conceito. In: DELILLE, K. H.; CHICHORRO, A. (Org.). Aprendizagem autônoma de línguas em tandem. Tradução de Manuela de Carvalho Simóes. Lisboa: Colibri, 2002. p.1525.

BRUNS, A. Towards produsage: futures for user-led content production. In: SUDWEEKS, F; HRACHOVEC, H.; ESS, C. (Ed.). Proceedings cultural attitudes towards communication and technology. [S.1.]: QUT, 2006. p.275-284. Disponível em: <http://eprints.qut.edu. au/4863/1/4863_1.pdf>. Acesso em: 12 nov. 2014.

BUZATO, M. E. K. Letramento e inclusão: do estado-nação à era das TICs. DELTA, São Paulo, v.25, n.1, p.1-38, 2009.

BUZATO, M. E. K. Letramentos digitais e formação de professores. EducaRede, 2006. Disponível em: <http://www.educarede.org.br/educa/img_conteudo/marcelobuzato.pdf $>$. Acesso em: 2 jul. 2009.

DOLZ, J.; SCHNEUWLY, B. Gêneros orais e escritos na escola. Tradução de Roxane Rojo. Campinas: Mercado de Letras, 2004.

ERICKSON, F. Qualitative methods in research on teaching. In: WITTROCK, M. C. (Ed.). Handbook of research in education. New York: Macmillan, 1986. p.119-161.

FIGUEIREDO, F. J. Q. A aprendizagem colaborativa de línguas: algumas consideraçóes conceituais e terminológicas. In: FIGUEIREDO, F. J. Q. (Org.). A aprendizagem colaborativa de línguas. Goiânia: Ed. da UFG, 2006. p.11-45.

FRIEDRICH, J. Lev Vigotsky: mediação, aprendizagem e desenvolvimento: uma leitura filosófica e epistemológica. Tradução de Anna Rachel Machado e Eliane Gouvêa Lousada. São Paulo: Mercado de Letras, 2012.

GIBSON, S.; McKAY, R. How research on the use of computer technologies can inform the work of social studies educators. Canada's National Social Studies Journal, v.35, n.2, não paginado, 2001. Disponível em: <http://www.educ.ualberta.ca/css/Css_35_2/research_ computer_technologies.htm>. Acesso em: 20 ago. 2010. 
HAMILTON, M. Sustainable literacies and the ecology of lifelong learning. London: 2000 .

HAWKINS, M.; NORTON, B. Critical language teacher education. In: BURNS, A.; RICHARDS, J. C. (Org.). The cambridge guide to second language teacher education. Cambridge: Cambridge University Press, 2009. p.30-39.

JOHNSON, K. E. Second language teacher education: a sociocultural perspective. New York: Routledge, 2009.

KLEIMAN, A. Os estudos sobre letramento e a formação de professor de língua materna. Linguagem em (Dis)curso: LemD, Tubarão, v. 8, n. 3, p. 487-517, set./dez. 2008.

LANKSHEAR, C.; KNOBEL, M. New literacies: everyday practices \& classroom learning. 2. ed. New York: McGraw Hill, 2006.

LÉVY, P. Web 2.0 não é inovação, diz Pierre Lévy. Entrevistador: Marcos Strecker. Folha de Sáo Paulo, São Paulo, 14 ago. 2007. Disponível em: <http://www1.folha.uol.com.br/fsp/ ilustrad/fq1408200711.htm>. Acesso em: 10 maio 2016.

LÉVY, P. Cibercultura. Tradução de Carlos Irineu da Costa. São Paulo: 34, 1999.

LÉVY, P. A inteligência coletiva: por uma antropologia do ciberespaço. Tradução de Luiz Paulo Rouanet. São Paulo: Loyola, 1998.

MAIA, J. O. Novos e híbridos letramentos em contexto de periferia. In: ROJO, H. R. Letramentos múltiplos, escola e inclusão social. São Paulo: Parábola, 2009. p.59-71.

OLIVEIRA E PAIVA, V. L. Avaliação dos cursos de Letras e a formação do professor. Revista do GELNE, João Pessoa, v. 5, n. 1-2, p. 193-200, 2004.

PIMENTA, S. G.; GHEDIN, E. (Org.). Professor reflexivo no Brasil: gênese e crítica de um conceito. São Paulo: Cortez, 2002.

ROJO, R. Letramentos múltiplos, escola e inclusão social. São Paulo: Parábola, 2009.

ROJO, H. R. et al. (Org). Esc@la conectada: os multiletramentos e as TICs. São Paulo: Parábola, 2013.

SAITO, F. S.; SOUZA, P. N. (Multi)letramento(s) digital(is): por uma revisão de literatura crítica. Linguagens e Diálogos, Rio de Janeiro, v. 2, n. 1, p. 109-143, 2011.

SANTOS, C. F. et al. (Org). Diversidade textual: os gêneros na sala de aula. Belo Horizonte: Autêntica, 2007.

SINGH, G.; RICHARDS, J. C. Teaching and learning in the course room. In: BURNS, A.; RICHARDS, J. C. (Org.). The cambridge guide to second language teacher education. Cambridge: Cambridge University Press, 2009. p.201-208.

SOARES, M. Novas práticas de leitura e escrita: letramento na cibercultura. Educaçáo \& Sociedade, Campinas, v.23, n.81, p.143-160, 2002. 
STREET, B. V. Social literacies: critical approaches to literacy in development, ethnography and education. Harow: Pearson, 1995.

SYKES, J. M.; OSKOZ, A.; THORNE, S. L. Synthetic immersive environments, and mobile resources for language education. Calico Journal, [S.1.], v. 25, n. 3, p. 528-546, 2008.

TELETANDEM NEWS. Assis: UNESP, ano I, n.1, 2006. Disponível em: <http://www. teletandembrasil.org/teletandem-news.html>. Acesso em: 27 set. 2016.

TELLES, J. A. (Org.). Teletandem: um contexto virtual, autônomo e colaborativo para aprendizagem de línguas estrangeiras no século XXI. Campinas: Pontes, 2009.

TELLES, J. A.; VASSALLO, M. L. Foreign language learning in-tandem: Teletandem as an alternative proposal in CALLT. The ESPecialist, São Paulo, v. 27, n. 2, p. 189-212, 2006.

THORNE, S. L.; PAYNE, J. S. Evolutionary trajectories, internet mediated expression and language education. Calico Journal, [S.1.], v. 22, n. 3, p. 371-397, 2005.

VALENTE, C.; MATTAR, J. Second life e Web 2.0 na educaçáo: o potencial revolucionário das novas tecnologias. São Paulo: Novatec, 2007.

VASSALLO, M. L.; TELLES, J. A. Teletandem: uma proposta alternativa no ensino/ aprendizagem assistido por computadores. In: TELLES, J. A. (org.). Teletandem: um contexto virtual, autônomo e colaborativo para aprendizagem de línguas estrangeiras no século XXI. Campinas: Pontes, 2009a. p.43-61.

VASSALLO, M. L.; TELLES, J. A. Ensino e aprendizagem de línguas em tandem: princípios teóricos e perspectiva de pesquisa. In: TELLES, J. A. (org.). Teletandem: um contexto virtual, autônomo e colaborativo para aprendizagem de línguas estrangeiras no século XXI. Campinas: Pontes, 2009b. p.21-42.

VASSALLO, M. L.; TELLES, J. A. Foreign language learning in-tandem: theoretical principles and research perspectives. The ESPecialist, São Paulo, v. 27, n. 1, p. 83-118, 2006.

VIEIRA, M. F. V. Ambiente Wiki na educação: produção colaborativa do conhecimento compartilhado na web. Revista Tecnologias na Educaçáo, ano 1, n. 1, 2008.

VIGOTSKI, L. V. A construçáo do pensamento e da linguagem. Tradução de Paulo Bezerra. 2.ed. São Paulo: WMF Martins Fontes, 2010.

VIGOTSKI, L. V. A formação social da mente. Tradução de José Cippola Neto et al. 6.ed. São Paulo: Martins Fontes, 1999.

VIGOTSKI, L. V. Pensamento e linguagem. Tradução de Jefferson Luiz Camargo. 2. ed. São Paulo: Martins Fontes, 1998.

VIGOTSKI, L. V. Pensamento e linguagem. Tradução de Jefferson Luiz Camargo. São Paulo: Martins Fontes, 1987. 
WARSCHAUER, M.; LIAW, M.-L. Emerging technologies in adult literacy and language education. Washington: National Institute for Literacy, jun. 2010.

WENGER, E. Communities of practice: a brief introduction. jun. 2006. Disponível em: $<$ http://wenger-trayner.com/introduction-to-communities-of-practice/>. Acesso: 12 jan. 2010.

WENGER, E. Communities of practice: learning, meaning, and identity. Cambridge: Cambridge University Press, 1998.

WILLIAMS, M.; BURDEN, R. L. Psychology for language teacher: a social constructivist approach. Cambridge: Cambridge University Press, 1997.

ZEICHNER, K. M. Uma análise crítica sobre a "reflexão" como conceito estruturante na formação docente. Educaçáo \& Sociedade, Campinas, v.29, n.103, p.535-554, maio/ago. 2008.

Recebido em 18/05/2016

Aprovado em 09/07/2016 
